\title{
Demonstration of Insulin Resistance in Untreated Adult Onset Diabetic Subjects with Fasting Hyperglycemia
}

\author{
Henry Ginsberg, George Kimmerling, Jerrold M. Olefsky, and \\ Gerald M. Reaven \\ From the Department of Medicine, Stanford University School of Medicine and \\ Veterans Administration Hospital, Palo Alto, California 94304
}

\begin{abstract}
A в S T R A C T We have used a continuous intravenous infusion of glucose $(6 \mathrm{mg} / \mathrm{kg} / \mathrm{min})$, insulin $(80 \mathrm{mU} /$ $\mathrm{min})$, epinephrine $(6 \mu \mathrm{g} / \mathrm{min})$, and propranolol $(0.08$ $\mathrm{mg} / \mathrm{min}$ ) to directly assess insulin resistance in 14 untreated adult onset diabetics with a mean $( \pm S E)$ fasting plasma glucose level of $217 \pm 17 \mathrm{mg} / 100 \mathrm{ml}$. During the infusion endogenous insulin secretion is inhibited and steady-state plasma glucose and insulin levels are achieved after $90 \mathrm{~min}$. Since similar steadystate levels of plasma insulin are achieved in all subjects, the plasma glucose concentration observed during the steady-state period is a measure of an individual's insulin resistance. Under these conditions, the mean ( $\pm \mathrm{SE}$ ) steady-state plasma glucose level of the 14 diabetic patients was $350 \pm 16 \mathrm{mg} / 100 \mathrm{ml}$, while that of 12 normal subjects was $121 \pm 4 \mathrm{mg} / 100 \mathrm{ml}$. Additional studies were performed in which control subjects and patients with diabetes had their fasting plasma glucose levels acutely raised or lowered to comparable levels before receiving the basic infusion mixture of glucose, insulin, epinephrine, and propranolol. The results of these studies indicated that differences in initial plasma glucose levels could not account for the different glucose responses of the two groups to the basic infusion. Finally, the mean ( $\pm \mathrm{SE}$ ) steady-state plasma glucose level of $104 \pm 17 \mathrm{mg} / 100 \mathrm{ml}$ observed during the same basic infusion in five patients with fasting hyper-
\end{abstract}

This work has been presented in part in abstract form in Clin. Res. 22: 469A, 1974.

Drs. Ginsberg and Kimmerling are Resident Clinical Associates, Veterans Administration (MRIS nos. 3142 and 4932, respectively). Dr. Olefsky is a Research and Education Associate, Veterans Administration (MRIS no. 6488). Dr. Reaven is a Medical Investigator, Veterans Administration (MRIS no. 7363).

Received for publication 28 June 1974 and in revised form 17 September 1974. glycemia (mean $\pm \mathrm{SE}, 142 \pm 12 \mathrm{mg} / 100 \mathrm{ml}$ ) secondary to chronic pancreatitis suggested that neither chronic hyperglycemia nor hypoinsulinemia per se necessarily lead to insulin resistance. These results demonstrate that marked insulin resistance exists in adult onset diabetics with fasting hyperglycemia. Since previous studies have documented the presence of insulin resistance in patients with chemical diabetes, the possibility exists that insulin resistance may be characteristic of adult onset diabetes mellitus.

\section{INTRODUCTION}

In 1960 Berson and Yalow reported that many patients with adult onset diabetes mellitus had a greater than normal insulin response during an oral glucose tolerance test (1), suggesting that insulin resistance existed in these subjects. Subsequently, utilizing an infusion technique that allowed a more direct measurement of insulin responsiveness, we confirmed the existence of insulin resistance in nonobese subjects with normal fasting plasma glucose and abnormal oral glucose tolerance tests (2). More recently, Alford, Martin, and Pearson (3) have reported a diminished hypoglycemic response to intravenous insulin in adult onset diabetics with fasting hyperglycemia, suggesting that insulin resistance may also exist in patients with more severe diabetes. Consequently, in the present study we have used our infusion technique to determine the degree of insulin resistance present in a group of nonketotic adult onset diabetic subjects with fasting hyperglycemia.

\section{METHODS}

Subjects. 14 subjects with idiopathic adult onset diabetes, five subjects with chronic pancreatitis and fasting hyperglycemia, and 12 normal subjects were studied at the Stanford Clinical Research Center. The pertinent clinical characteristics of each group are shown in Table I. The 14 sub- 
jects with adult onset diabetes mellitus had been diagnosed 1-12 yr before study. None had any other disease known to affect carbohydrate metabolism. 12 of the 14 diabetic patients had never been treated, and two patients who had been receiving oral hypoglycemic agents discontinued their medication 1 mo before these studies. The five patients with chronic pancreatitis had a documented history of recurrent acute pancreatitis, and evidence of pancreatic calcification and/or malabsorption. They had fasting hyperglycemia of 2-4 yr duration. None of these patients had a family history of diabetes, nor was glucose intolerance known to exist before the onset of pancreatic insufficiency. There was no clinical or laboratory evidence of abnormal liver function in any subjects. All patients were in otherwise good general health. They were eating well, and, where indicated, were receiving appropriate therapy for pancreatic exocrine deficiency. There was no history of recent weight change. The 12 control subjects were healthy adult male volunteers, all of whom had a normal glucose response to an oral glucose load (4).

Diet. All subjects consumed a weight maintenance liquid formula diet consisting of $43 \%$ carbohydrate, $42 \%$ fat, and

TABLE I

Clinical Characteristics

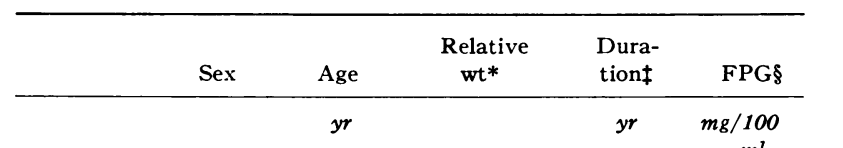

Adult diabeties

\begin{tabular}{llcrrc} 
A. K. & M & 50 & 0.85 & 3 & 125 \\
F. M. & F & 54 & 1.08 & 4 & 140 \\
S. L. & M & 54 & 1.06 & 1 & 143 \\
J. S. & M & 66 & 1.20 & 3 & 173 \\
W. R. & F & 47 & 1.07 & 2 & 190 \\
H. V. & M & 59 & 1.16 & 3 & 195 \\
T. S. & M & 60 & 1.04 & 2 & 203 \\
E. G. & M & 49 & 1.37 & 1 & 203 \\
J. M. & M & 46 & 0.85 & 2 & 216 \\
I. L. & M & 42 & 1.25 & 3 & 270 \\
L. K. & M & 53 & 0.83 & 5 & 280 \\
A. G. & F & 63 & 0.92 & 2 & 300 \\
R. D. & M & 42 & 0.92 & 12 & 303 \\
V. A. & M & 48 & 0.88 & 2 & 303 \\
\multicolumn{2}{l}{ Mean \pm SE } & $52 \pm 2$ & $1.03 \pm 4$ & $3.2 \pm 1$ & $217 \pm 17$
\end{tabular}

Pancreatitis and hyperglycemia

\begin{tabular}{lccccc} 
A. C. & M & 52 & 0.90 & 4 & 125 \\
V. J. & M & 60 & 1.01 & 3 & 125 \\
B. T. & M & 57 & 0.99 & 2 & 126 \\
D. R. & M & 40 & 0.77 & 3 & 146 \\
E. W. & M & 44 & 0.90 & 4 & 187 \\
\multicolumn{2}{l}{ Mean \pm SE } & $51 \pm 4$ & $0.91 \pm 4$ & $3.2 \pm 1$ & $142 \pm 12$
\end{tabular}

Normal subjects
$(n=12)$
$44 \pm 3 \quad 0.99 \pm 0.04$
$92 \pm 2$

* Calculated by dividing subjects' actual weights by agecorrected average weights as given in the Metropolitan Life Tables.

$\ddagger$ Years from date of diagnosis of hyperglycemia.

$\S$ Mean of three fasting plasma glucose levels.

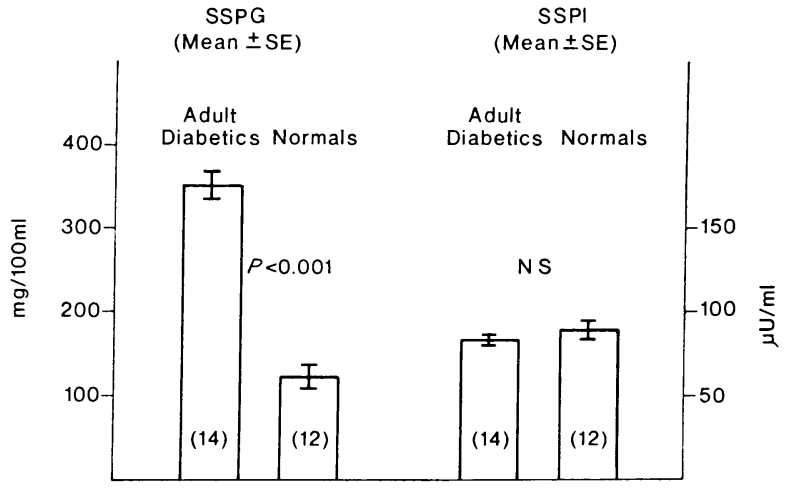

Figure 1 The mean ( \pm SE) SSPG and SSPI of 14 adult onset diabetic and 12 normal subjects. All subjects received the basic $180-\mathrm{min}$ infusion of glucose $(6 \mathrm{mg} / \mathrm{kg} / \mathrm{min})$, insulin $(80 \mathrm{mU} / \mathrm{min})$, epinephrine $(6 \mu \mathrm{g} / \mathrm{min})$, and propranolol $(0.08 \mathrm{mg} / \mathrm{min})$. Steady-state levels of plasma glucose and insulin are reached by $90 \mathrm{~min}$ and the mean values of several blood samples drawn between 90 and $180 \mathrm{~min}$ are used as the SSPG and SSPI.

$15 \%$ protein. The daily caloric intake of $35 \mathrm{kcal} / \mathrm{kg} / \mathrm{day}$ was divided into portions of $1 / 5,2 / 5$, and $2 / 5$ served at 8 A.M., 12 noon, and 6 P.M. Daily weights were obtained on all subjects and were constant throughout the study period.

Protocol. After 3 days of weight stabilization, and after a 12-h overnight fast, all subjects received an intravenous injection of $5 \mathrm{mg}$ of propranolol followed in $5 \mathrm{~min}$ by the basic infusion mixture ${ }^{1}$ consisting of a constant intravenous infusion of glucose $(6 \mathrm{mg} / \mathrm{kg} / \mathrm{min})$, insulin $(80 \mathrm{mU} / \mathrm{min})$, epinephrine $(6 \mu \mathrm{g} / \mathrm{min})$, and propranolol $(0.08 \mathrm{mg} / \mathrm{min})$. The solution was infused continuously for $180 \mathrm{~min}$ via a Harvard pump (Harvard Apparatus Co., Inc., Millis, Mass.) into an antecubital vein. Blood samples were drawn from the opposite arm through a needle kept patent by a slow saline infusion. Under these experimental conditions, endogenous insulin secretion is suppressed and steady-state plasma glucose $(\mathrm{SSPG})^{2}$ and insulin (SSPI) levels are reached by $90 \mathrm{~min}$ (2). Since similar SSPI are achieved in all subjects (2), this technique allows us to compare the ability of different subjects to dispose of identical glucose loads under the same insulin stimulus. Therefore, the mean of several plasma glucose concentrations measured during the steady-state period from 90 to $180 \mathrm{~min}$ is a measure of efficiency of insulin-mediated glucose utilization, i.e., insulin resistance.

This approach has previously allowed us to directly compare the degree of insulin resistance in normal subjects and in patients with chemical diabetes. However, both of these groups had normal fasting plasma glucose concentrations, while the diabetics in the present study had fasting hyperglycemia. Since it was possible that hyper-

${ }^{1}$ In the original article in which this infusion mixture was described (2), the insulin dose was erroneously said to be $50 \mathrm{mU} / \mathrm{min}$. The amount of insulin actually infused was $80 \mathrm{mU} / \mathrm{min}$, and this represents the amount of insulin used in all of our published studies.

${ }^{2}$ Abbreviations used in this paper: SSPG, steady-state plasma glucose levels (degree of insulin resistance); SSPI, steady-state plasma insulin levels. 


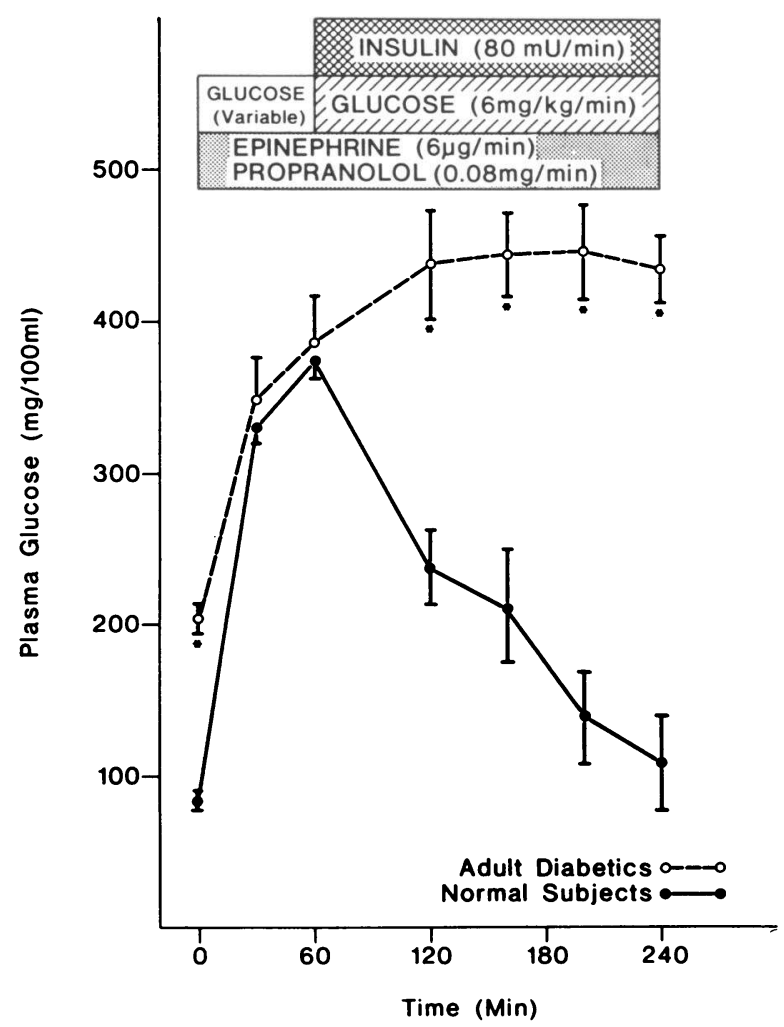

Figure 2 The mean ( $\pm \mathrm{SE}$ ) plasma glucose levels of five adult onset diabetic and five normal subjects whose plasma glucose concentrations were equalized at a high level before receiving the basic $180-\mathrm{min}$ infusion of glucose $(6 \mathrm{mg} / \mathrm{kg}$ / $\mathrm{min})$, insulin $(80 \mathrm{mU} / \mathrm{min})$, epinephrine $(6 \mu \mathrm{g} / \mathrm{min})$, and propranolol $(0.08 \mathrm{mg} / \mathrm{min})$. All subjects were infused with epinephrine and propranolol for the first $60 \mathrm{~min}$ and, in addition, the normal subjects received large amounts of intravenous glucose while the diabetic subjects received smaller quantities of glucose intravenously. In this manner, the fasting plasma glucose levels of both groups were raised to comparable high levels after $60 \mathrm{~min}$. At that time the basic infusion mixture was given to all subjects for an additional $180 \mathrm{~min}$ with frequent blood samples obtained for measurement of plasma glucose levels. $* P<0.001$.

glycemia per se affected our measurement of insulin resistance additional studies in which fasting plasma glucose concentration was acutely changed before the basic infusion study were carried out as follows.

(a) The effect of a markedly increased plasma glucose concentration on the response to the basic infusion of glucose, insulin, epinephrine, and propranolol was studied by raising the plasma glucose levels of five normal and five diabetic subjects to the same high levels. This was accomplished by infusing epinephrine, propranolol, and varying amounts of glucose (ranging from 2 to $6 \mathrm{mg} / \mathrm{kg} / \mathrm{min}$ ), without insulin, to all subjects during the first $60 \mathrm{~min}$ of the infusion. In addition, various amounts of intravenous glucose were given as a bolus to the normal subjects at the beginning. Plasma glucose levels were monitored frequently, and the glucose infusion rate varied in an effort to produce comparable glucose levels at $60 \mathrm{~min}$. From this point on, all subjects were infused with the basic mixture of glucose, insulin, epinephrine, and propranolol for an additional $180 \mathrm{~min}$. Blood was sampled frequently throughout this period for measurement of plasma glucose and insulin.

(b) The effect of a moderately increased plasma glucose concentration on the response to the basic infusion mixture was studied by equalizing the fasting plasma glucose levels of four normal and four diabetic subjects at an intermediate level of hyperglycemia. The normal subjects were infused with only epinephrine and propranolol for the initial $60 \mathrm{~min}$, as previous experience has shown that this infusion mixture suppresses endogenous insulin secretion and results in a modest elevation of plasma glucose levels. To achieve comparable plasma glucose levels in the diabetic subjects, the latter group was infused with epinephrine, propranolol, and varying amounts of insulin for $60 \mathrm{~min}$. With this approach the plasma glucose levels of the four diabetics were lowered to the levels attained in the four normal subjects. At this time the basic infusion mixture of glucose, insulin, epinephrine, and propranolol was given to both groups for $180 \mathrm{~min}$. These additional studies enabled us to assess the ability of the two groups to dispose of the same glucose load in the presence of similar plasma insulin levels with both groups beginning at comparable levels of hyperglycemia.

Analytical procedures. Blood for determination of plasma glucose and insulin was drawn into test tubes containing EDTA, the plasma quickly separated, and aliquots stored at $-20^{\circ} \mathrm{C}$ until determinations were done. Plasma glucose (5) and FFA levels (6) were measured by methods modified for use on a Technicon AutoAnalyzer (Technicon Instruments Corp., Tarrytown, N. Y.). Plasma insulin was measured by the method of Desbuquois and Aurbach (7). Statistical analysis was performed with Student's $t$ test for nonpaired data $(8)$.

\section{RESULTS}

The mean SSPG and SSPI of 14 subjects with adult onset diabetes and of twelve normal subjects during the basic $180-\mathrm{min}$ infusion of glucose, insulin, epinephrine, and propranolol are shown in Fig. 1. Although similar SSPI were achieved in both groups,

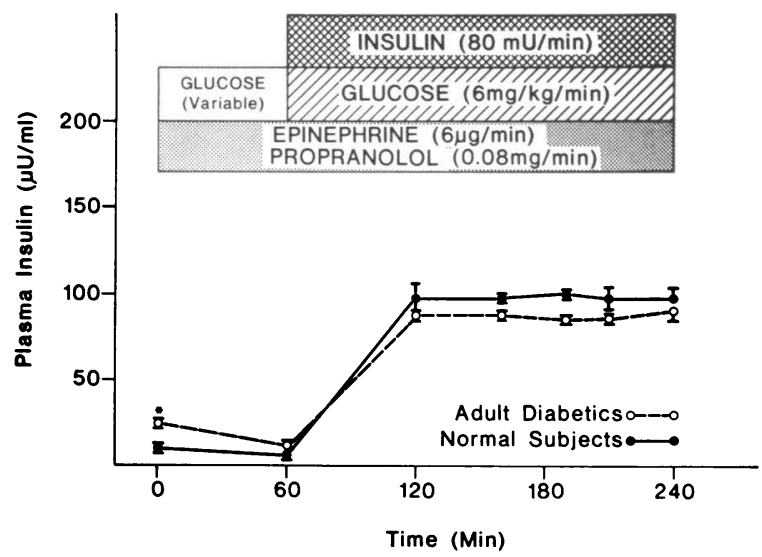

Figure 3 The mean ( \pm SE) plasma insulin levels of five diabetic and five normal subjects during the studies depicted in Fig. 2. $* P<0.01$. 


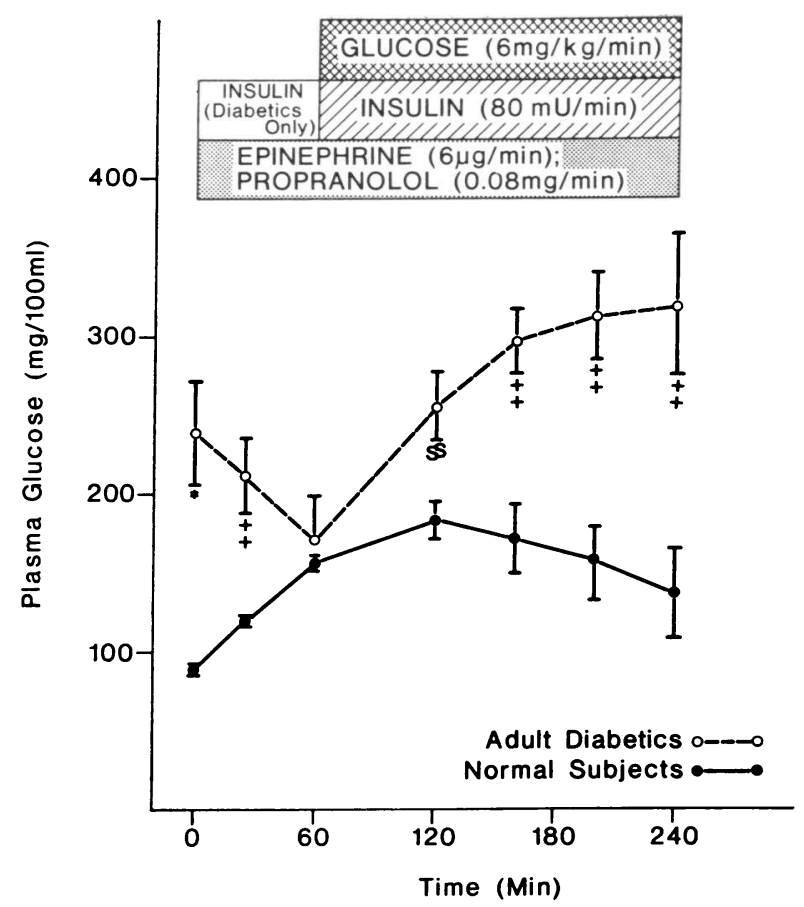

FIgURE 4 The mean ( \pm SE) plasma glucose levels of four adult onset diabetic and four normal subjects whose plasma glucose concentrations were equalized at an intermediate level before receiving the basic 180 -min infusion of glucose $(6 \mathrm{mg} / \mathrm{kg} / \mathrm{min})$, insulin $(80 \mathrm{mU} / \mathrm{min})$, epinephrine $(6 \mu \mathrm{g} /$ $\mathrm{min})$, and propranolol $(0.08 \mathrm{mg} / \mathrm{min})$. All subjects were infused with epinephrine and propranolol for the first 60 min and, in addition, the diabetic subjects received varying amounts of intravenous insulin. Under these conditions, the fasting plasma glucose level of the normal subjects had risen modestly after $60 \mathrm{~min}$ while the fasting plasma glucose concentration of the diabetics had decreased to a similar level at that time. All subjects then received the basic infusion mixture for an additional $180 \mathrm{~min}$ with frequent blood samples obtained for measurement of plasma glucose levels. ${ }^{*} P<0.001 ; \ddagger P<0.01 ; \$ P<0.05$.

it can be seen that the mean ( \pm SE) SSPG of the diabetic subjects was approximately three times that of the normal group $(350 \pm 16$ vs. $121 \pm 4 \mathrm{mg} / 100 \mathrm{ml})$. This difference is highly significant $(P<0.001)$, suggesting that the patients with diabetes were markedly insulin resistant.

Since the fasting plasma glucose levels of the two groups were quite different, additional studies were done to determine if the height of the initial glucose level could affect the response to the basic infusion mixture. In these studies insulin resistance was assessed after equalization of the initial glucose concentration in normal subjects and in patients with idiopathic diabetes. Thus, Fig. 2 depicts the plasma glucose levels of five diabetic and five normal subjects who had their fasting plasma glucose concentrations raised to comparable very high levels before infusion of the basic mixture of glucose, insulin, epinephrine, and propranolol. The initial fasting mean $( \pm \mathrm{SE})$ plasma glucose level of the normal group was $84 \pm 3 \mathrm{mg} / 100 \mathrm{ml}$, while that of the diabetic group was $203 \pm 16 \mathrm{mg} / 100$ $\mathrm{ml}$. After $60 \mathrm{~min}$ of the intravenous infusion of epinephrine, propranolol, and varying amounts of glucose, the mean $( \pm \mathrm{SE}$ ) plasma glucose level was $374 \pm 11$ $\mathrm{mg} / 100 \mathrm{ml}$ in the normal group and $386 \pm 33 \mathrm{mg} / 100 \mathrm{ml}$ in the diabetic group. The difference in the subsequent response of each group to the basic infusion mixture of glucose, epinephrine, propranolol, and insulin during the next $180 \mathrm{~min}$ is obvious. The mean $( \pm \mathrm{SE})$ plasma glucose level of the diabetic subjects increased to 435 $\pm 22 \mathrm{mg} / 100 \mathrm{ml}$, while the plasma glucose level in the normal group steadily declined to $106 \pm 30 \mathrm{mg} / 100 \mathrm{ml}$. The difference between the 240-min plasma glucose levels of the two groups is significant at the $P<0.001$ level. The plasma insulin concentrations of each group during these studies are shown in Fig. 3. The mean fasting plasma insulin level was significantly higher in the diabetic group. Suppression of endogenous insulin secretion in both groups, in spite of severe hyperglycemia, is evident after $60 \mathrm{~min}$ of epinephrine and propranolol. Finally, during the last $120 \mathrm{~min}$ of the studies, comparable SSPI were attained in both groups, indicating that the differing plasma glucose responses of the two groups during this period (Fig. 2) did not result from different levels of plasma insulin.

The plasma glucose levels of four diabetic subjects and four normal subjects who received the basic infusion mixture of glucose, insulin, epinephrine, and pro-

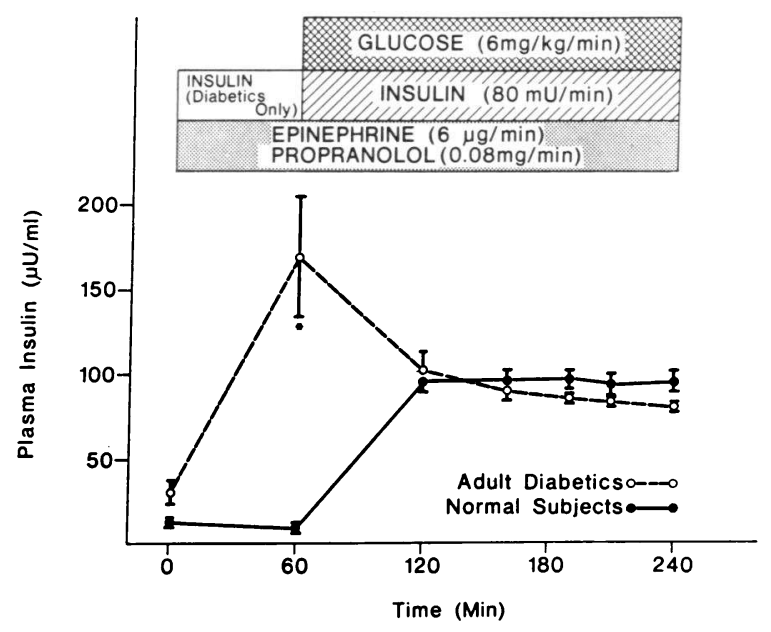

FIGURE 5 The mean ( $\pm \mathrm{SE}$ ) plasma insulin levels of four diabetic and four normal subjects during the studies depicted in Fig. 4. The high levels of plasma insulin in the diabetics after $60 \mathrm{~min}$ is due to the intravenous insulin given to this group only. $* P<0.05$. 


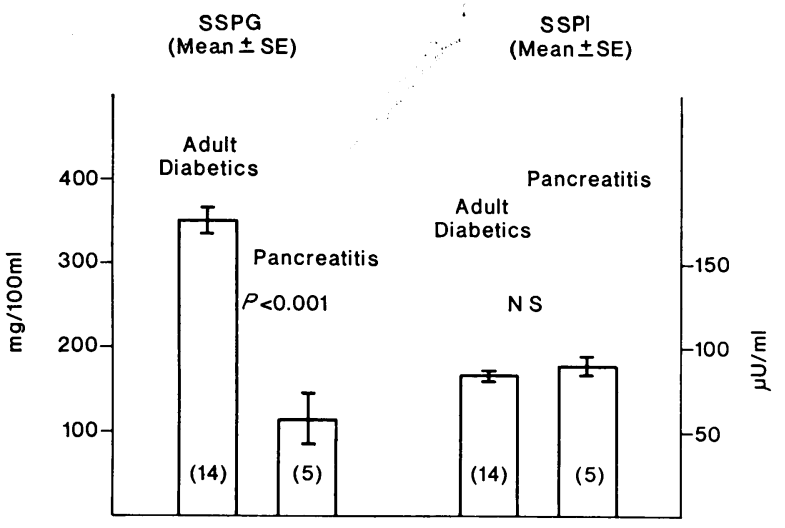

FIGURE 6 The mean ( \pm SE) SSPG and SSPI of 14 adult onset diabetic subjects and five subjects with fasting hyperglycemia secondary to chronic pancreatitis during the basic $180-\mathrm{min}$ infusion of glucose $(6 \mathrm{mg} / \mathrm{kg} / \mathrm{min})$, insulin $(80$ $\mathrm{mU} / \mathrm{ml})$, epinephrine $(6 \mu \mathrm{g} / \mathrm{min})$, and propranolol $(0.08$ $\mathrm{mg} / \mathrm{min}$ ). Steady-state levels of plasma glucose and insulin are reached by $90 \mathrm{~min}$ and the mean values of several blood samples drawn between 90 and $180 \mathrm{~min}$ are used as the SSPG and SSPI.

pranolol after equalization of their fasting plasma glucose levels at a moderate level of hyperglycemia are shown in Fig. 4. The normal subjects' initial mean $( \pm \mathrm{SE})$ fasting plasma glucose concentration was 88 $\pm 2 \mathrm{mg} / 100 \mathrm{ml}$ while that of the diabetic group was $237 \pm 29 \mathrm{mg} / 100 \mathrm{ml}$. After a 60 -min infusion of only epinephrine and propranolol, the mean $( \pm \mathrm{SE})$ plasma glucose concentration of the normal group had risen to $156 \pm 5 \mathrm{mg} / 100 \mathrm{ml}$. After a 60 -min infusion of epinephrine, propranolol, and varying amounts of insulin, the mean $( \pm \mathrm{SE})$ plasma glucose level of the diabetic group had decreased to $173 \pm 22 \mathrm{mg} / 100 \mathrm{ml}$. There was no significant difference between these levels. All subjects then received the basic infusion mixtures of glucose, insulin, epinephrine and propranolol, and the divergent responses of the two groups during the next $180 \mathrm{~min}$ is evident. At the end of the infusion, the mean $( \pm \mathrm{SE})$ plasma glucose level of the diabetic subjects had increased to $319 \pm 36 \mathrm{mg} / 100 \mathrm{ml}$, while the plasma glucose level of the normal group had decreased to $136 \pm 27 \mathrm{mg} / 100 \mathrm{ml}$. These differences are significant at the $P<0.01$ level. The plasma insulin concentrations of the two groups during these infusions are presented in Fig. 5. Again, fasting plasma insulin levels of the diabetic subjects were higher than those in the normal group, though the difference did not reach statistical significance. After $60 \mathrm{~min}$, suppression of endogenous insulin secretion in the normal subjects and administration of exogenous insulin to the diabetic subjects resulted in markedly differing plasma insulin levels in the two groups. However, during the final $120 \mathrm{~min}$ of the studies, both groups had similar SSPI, again indicating that differences in glucose levels (Fig. 4) were not caused by differences in plasma insulin levels. The results of the studies depicted in Figs. 2-5 provide evidence that the marked increase in the SSPG of patients with idiopathic diabetes (Fig. 1) is not simply the result of an increased initial plasma glucose concentration.

However, the above results did not rule out the possibility that chronic hypoinsulinemia, and/or chronic hyperglycemia, can lead to the development of insulin resistance. Therefore, in order to investigate this possibility, the basic infusion was given to five subjects with fasting hyperglycemia secondary to chronic pancreatic insufficiency. The mean SSPG and SSPI of these five subjects during the basic infusion is compared to that of the 14 subjects with idiopathic adult onset diabetes in Fig. 6. It is clear that while both groups had similar SSPI, the mean $( \pm \mathrm{SE})$ SSPG of the subjects with pancreatitis is comparable to that of the control subjects, and significantly lower than the level attained by the adult onset diabetics $(104 \pm 17$ vs. $350 \pm 16 \mathrm{mg} / 100 \mathrm{ml} ; P<0.001)$. However, because the mean fasting plasma glucose level of the 14 subjects with adult onset diabetes $(217 \mathrm{mg} / 100 \mathrm{ml})$ was significantly greater than the mean fasting plasma glucose level of the five pancreatitic subjects $(142 \mathrm{mg} / 100 \mathrm{ml})$, we also compared the individual infusion results of the latter subjects with five adult onset diabetics having comparable fasting plasma glucose concentrations. These data are presented in Table II. Although these groups

TABLE II

Comparison between Five Patients with Pancreatitis and Five Patients with Adult Onset Diabetes

\begin{tabular}{|c|c|c|c|c|c|c|}
\hline & Age & $\begin{array}{c}\text { Relative } \\
\text { wt* }\end{array}$ & $\begin{array}{l}\text { Dura- } \\
\text { tion } \ddagger\end{array}$ & $\begin{array}{l}\text { Fasting } \\
\text { plasma } \\
\text { glucose }\end{array}$ & SSPG & SSPFFA $\delta$ \\
\hline & $y r$ & & $y r$ & $\begin{array}{c}m g / \\
100 m l\end{array}$ & $\begin{array}{c}m g / \\
100 \mathrm{ml}\end{array}$ & $\begin{array}{l}\text { ueq/ } \\
\text { liter }\end{array}$ \\
\hline \multicolumn{7}{|c|}{ Pancreatitis patients } \\
\hline A. C. & 52 & 0.90 & 4 & 125 & 155 & 54 \\
\hline V. J. & 60 & 1.01 & 3 & 125 & 104 & 95 \\
\hline B. $T$. & 57 & 0.99 & 2 & 126 & 45 & 83 \\
\hline D. $\mathbf{R}$. & 40 & 0.77 & 2 & 146 & 116 & 74 \\
\hline E. W. & 44 & 0.90 & 4 & 187 & 100 & 107 \\
\hline Mean \pm SE & $51 \pm 4$ & $0.91 \pm 4$ & $3.2 \pm 1$ & $142 \pm 12$ & $104 \pm 17$ & $83 \pm 9$ \\
\hline \multicolumn{7}{|c|}{ Adult onset diabetics } \\
\hline A. $\mathrm{K}$. & 50 & 0.85 & 3 & 125 & 279 & 124 \\
\hline F. M. & 54 & 1.08 & 4 & 140 & 248 & 95 \\
\hline S. L. & 54 & 1.06 & 1 & 143 & 260 & 108 \\
\hline J. S. & 66 & 1.20 & 3 & 173 & 319 & 127 \\
\hline W. R. & 47 & 1.07 & 2 & 190 & 374 & 173 \\
\hline Mean \pm SE & $55 \pm 3$ & $1.05 \pm 6$ & $2.4 \pm 1$ & $154 \pm 12$ & $296 \pm 23$ & $125 \pm 13$ \\
\hline
\end{tabular}

* As determined by Metropolitan Life Tables. ¥ Years from date of diagnosis of hyperglycemia. \& Steady-state plasma FFA levels. 
are comparable in age, relative weight, duration of disease, and fasting plasma glucose level, their SSPG are still markedly different. In addition, steady-state FFA levels were determined in these 10 subjects. These data also appear in Table II, and indicate that steady-state FFA levels were markedly reduced in both groups. The slightly higher mean FFA levels which are seen in the patients with idiopathic diabetes may be a reflection of their insulin resistance, and suggests that lipolysis might not be suppressed quite as completely in these subjects.

\section{DISCUSSION}

The results of the present studies indicate that the mean SSPG of patients with idiopathic adult onset diabetes was more than three times that of normal subjects during the last $90 \mathrm{~min}$ of the 180 -min basic infusion study. Since the SSPI of the two groups were quite similar, these results demonstrate a marked impairment in the ability of the diabetic patients to respond to insulin. Thus, under the conditions of these studies the patients with diabetes were insulin resistant. The validity of this conclusion obviously depends upon the validity of the experimental approach. We have estimated insulin resistance by measuring the steady-state plasma glucose response to a prolonged infusion of glucose, insulin, epinephrine, and propranolol. This was done in an attempt to overcome the problems inherent in comparing the non-steadystate plasma glucose and insulin responses of normal and diabetic subjects to acute glucose challenges. Furthermore, this approach, which is based upon the inhibition of endogenous insulin secretion, avoids the variable of possible differences between individuals in the biological activity of endogenous insulin. However, these manipulations may introduce other factors which confound interpretation of the results. For example, it might be argued that the higher steady-state plasma glucose response seen in patients with idiopathic diabetes was a result of some effect of propranolol and/or epinephrine. This alternative explanation seems unlikely in view of the fact that all three patient groups received the same infusion. Thus, the postulated effects of either drug would have to result in a falsely elevated steady-state plasma glucose response in only those patients whose hyperglycemia was secondary to idiopathic diabetes, or a falsely lowered response in both normal subjects and patients with hyperglycemia secondary to chronic pancreatitis.

Another possible source of criticism relates to the potential effect of differences in initial plasma glucose levels on our estimate of insulin resistance. Thus, it could be argued that the higher SSPG in patients with idiopathic diabetes was simply a function of their fast- ing hyperglycemia. This alternative seems unlikely in view of additional studies in which the responses of normal subjects and patients with idiopathic diabetes to the basic infusion were compared after equalization of initial glucose level. For example, when both the normal and diabetic subjects had their plasma glucose concentrations increased to a similar high level, quite differing responses were observed during the ensuing basic infusions. The plasma glucose concentration of the diabetic subjects continued to increase while the plasma glucose concentration of the normals promptly decreased. Similarly, when the plasma glucose concentrations of the two groups were equalized at an intermediate level, the basic infusion resulted in a rapid rise in plasma glucose levels in the diabetics while in the normal subjects the plasma glucose steadily decreased. Finally, in this regard, insulin resistance was not seen in patients with chronic pancreatitis, indicating that the existence of chronic hyperglycemia does not necessarily lead to an elevation of the mean SSPG to the basic infusion. Taken together, these results demonstrate that differences in the initial glucose concentration cannot account for the markedly different steadystate glucose response to the basic infusion noted in the normal subjects and the patients with idiopathic diabetes.

Although these results indicate that insulin resistance exists in adult onset diabetic patients with fasting hyperglycemia, they provide no insight as to why insulin is ineffective in these individuals. Theoretically, the higher SSPG in patients with idiopathic diabetes could be due to the presence of circulating insulin antagonists or to direct tissue resistance to the action of insulin. In either case, this could involve resistance to the effect of insulin to promote glucose uptake by muscle, adipose tissue, and liver or resistance to the ability of insulin to suppress hepatic glucose output. We have previously found that suppression of endogenous glucose production occurs during the basic infusion in subjects with chemical diabetes (2), and the elevated SSPG in these patients must have been due to decreased glucose uptake in one or more of the insulin responsive tissues, e.g., liver, muscle, or adipose tissue. Since the status of endogenous glucose production in the diabetics with fasting hyperglycemia during the infusions reported here is unknown, the elevated SSPG could be due to either decreased glucose uptake by liver, muscle, or adipose tissue and/or nonsuppressed endogenous glucose production. Obviously, questions concerning the specific cause of the insulin resistance, and the tissues involved, will only be answered by further investigation.

The current documentation of insulin resistance in patients with fasting hyperglycemia extends our pre- 
vious demonstration of insulin resistance in patients with chemical diabetes (2), and suggests that insulin resistance is a common characteristic of patients with adult onset diabetes. However, at least one extremely important distinction exists between patients with chemical diabetes and those with significant fasting hyperglycemia, and this relates to their insulin response to a glucose challenge. Thus, the insulin response of patients with chemical diabetes is equal to or greater than normal (9-13). In these patients it seems reasonable to suggest that hyperglycemia is secondary to insulin resistance, and the exaggerated insulin response can be viewed as a compensatory mechanism aimed at minimizing glucose intolerance. On the other hand, this explanation cannot be used to account for the hyperglycemia in the adult onset diabetic subjects presented in this report, since diabetic patients with fasting hyperglycemia have insulin responses to glucose which are less than normal $(14,15)$. Therefore, it would appear that the hyperglycemia in these patients could result from both decreased insulin secretion and increased insulin resistance, and it is not immediately apparent which of the two is most important. One potential solution would be to postulate that insulin deficiency is the primary event, and that insulin resistance arises as the result of long-standing hypoinsulinemia, especially in light of recent evidence that such subjects may have abnormalities in the control of counter regulatory hormones such as glucagon (16), and growth hormone (17). However, although these hormones, in conjunction with elevated plasma FFA levels (18) and acidosis (19), may play an important role in decompensated diabetes, the present results make it less likely that similar mechanisms account for the insulin resistance in our subjects with idiopathic adult onset diabetes. Thus, if one compares the SSPG of the five patients with hyperglycemia secondary to chronic pancreatitis to that of five patients with idiopathic diabetes and comparable hyperglycemia (Table II), it can be seen that patients with idiopathic hyperglycemia are more insulin resistant than are patients with chronic pancreatitis. Furthermore, the fact that FFA levels were suppressed in both groups indicates that the insulin resistance was not due to enhanced lipolysis as a result of the epinephrine in patients with idiopathic diabetes. Since the patients with chronic pancreatitis were insulin deficient, but not insulin resistant, it is obvious that insulin deficiency per se does not necessarily lead to insulin resistance. However, this latter conclusion is based upon comparison of the degree of insulin resistance in patients with idiopathic diabetes to that in patients with hyperglycemia secondary to chronic pancreatitis. The degree of hyperglycemia was relatively moderate in this latter group, and it is con- ceivable that as diabetes becomes worse, i.e., fasting glucose $>200 \mathrm{mg} / 100 \mathrm{ml}$, insulin resistance might evolve as a secondary event. Thus, the current results do not rule out the possibility that insulin resistance in patients with more severe hyperglycemia might be secondary to insulin deficiency, nor do they allow an estimate of the relative importance of either decreased insulin secretion or increased insulin resistance in the etiology of the hyperglycemia in patients with idiopathic diabetes whose fasting plasma glucose ranges from 125 to $200 \mathrm{mg} / 100 \mathrm{ml}$. However, these results, coupled with our earlier studies of patients with chemical diabetes (2) do seem to indicate that insulin resistance is a common finding in patients with adult onset diabetes and that the insulin resistance can occur as a primary phenomenon in patients with a moderate degree of hyperglycemia.

\section{ACKNOWLEDGMENTS}

We wish to thank Ms. Jorene Moore, Ms. Virginia Peterson, and the nursing staff of the Stanford clinical research center for their invaluable assistance.

This work was supported by the following grants and contracts from the National Institutes of Health: General Clinical Research Centers Branch RR-70, and National Heart and Lung Institute HL 08506.

\section{REFERENCES}

1. Yalow, R. S., and S. A. Berson. 1960. Plasma insulin concentrations in nondiabetic and early diabetic subjects. Determinations by a new sensitive immuno-assay technic. Diabetes. 9: 254-260.

2. Shen, S.-W., G. M. Reaven, and J. W. Farquhar. 1970. Comparison of impedance to insulin-mediated glucose uptake in normal subjects and in subjects with latent diabetes. J. Clin. Invest. 49: 2151-2160.

3. Alford, F. P., F. I. R. Martin, and M. J. Pearson. 1971. The significance and interpretation of mildly abnormal oral glucose tolerance. Diabetologia. 7 : 173-180.

4. Standardization of the oral glucose tolerance test. Report of the Committee on Statistics of the American Diabetes Association. 1969. Diabetes. 18: 299-310.

5. Hoffman, W. S. 1937. A rapid photoelectric method for the determination of glucose in blood and urine. J. Biol. Chem. $120: 51-55$.

6. Dalton, C., and C. Kowalski. 1967. Automated colorimetric determination of free fatty acids in biologic fluids. Clin. Chem. 13: 744-751.

7. Desbuquois, B., and G. D. Aurbach. 1971. Use of polyethylene glycol to separate free and antibody-bound peptide hormones in radioimmunoassays. J. Clin. Endocrinol Metab. 33: 732-738.

8. Armitage, P. 1971. Statistical Methods in Medical Research. Blackwell Scientific Publications Ltd., Oxford, England. 99.

9. Berson, S. A., and R. S. Yalow. 1965. Some current controversies in diabetes research. The Banting Memorial Lecture. Diabetes. 14: 549-572.

10. Reaven, G. M., S.-W. Shen, A. Silvers, and J. W. Farquhar. 1971. Is there a delay in the plasma insulin response of patients with chemical diabetes mellitus? Diabetes. 20: 416-423. 
11. Chiles, R., and M. Tzagournis. 1970. Excessive serum insulin response to oral glucose in obesity and mild diabetes. Study of 501 patients. Diabetes. 19: 458-464.

12. Danowski, T. S., R. C. Khuranan, S. Nolan, T. Stephan, C. G. Gegick, S. Chae, and C. Vidalon. 1973. Insulin patterns in equivocal glucose tolerance tests (chemical diabetes). Diabetcs. $22: 808-812$.

13. Tchobroutsky, G., A. Kopf, E. Eschwege, and R. Assan. 1973. Serial postprandial plasma insulin levels in 117 subjects with and without diabetes. Diabetes. 22: 825833.

14. Reaven, G., and R. Miller. 1968. Study of the relationship between glucose and insulin responses to an oral glucose load in man. Diabetes. $17: 560-569$.

15. Karam, J. H., G. M. Grodsky, F. Ch. Pablatos, and P. H. Forsham. 1965. Critical factors in excessive seruminsulin response to glucose. Obesity in maturity-onset diabetes and growth hormone in acromegaly. Lancet. 1: 286-289.

16. Unger, R. H., E. Aguilar-Parada, W. A. Müller, and A. M. Eisentraut. 1970. Studies of pancreatic alpha cell function in normal and diabetic subjects. J. Clin. Invest. 49 : 837-848.

17. Johansen, K., and Aa. P. Hansen. 1971. Diurnal serum growth hormone levels in poorly and well-controlled juvenile diabetes. Diabetes. 20: 239-245.

18. Randle, P. J., P. B. Garland, C. N. Hales, and E. A. Newsholme. 1963. The glucose fatty-acid cycle. Its role in insulin insensitivity and the metabolic disturbance of diabetes mellitus. Lancet. 1: 785-789.

19. Weisinger, J., R. S. Swenson, W. Greene, J. B. Taylor, and G. M. Reaven. 1972. Comparison of the effects of metabolic acidosis and acute uremia on carbohydrate tolerance. Diabetes. 21: 1109-1115. 